\title{
PROPOSAL OF MODEL FOR THE ANTI-COLLISION SYSTEM USING THE RELATIVE NAVIGATION PRINCIPLE
}

\author{
Milan DŽUNDA, Peter DZUROVČIN, Alica TOBISOVÁ
}

Faculty of Aeronautics, Technical University of Kosice, Rampova 7, 04121 Kosice, Slovak Republic

*Corresponding author. E-mail: peter.dzurovcin@tuke.sk

\begin{abstract}
In this paper we describe the design of the on-board anti-collision system. We assume that all flying objects work in the aviation communications network and each of the flying objects transmits their location information. The basic condition for the operation of the proposed anticollision system is a synchronous communication network. Each network user is precisely determined by the time of broadcasting communications messages. This means that every user who works on this network has information about the time of broadcasting signals to other users. Based on this, we have designed an anti-collision system that will work on the principle of relative navigation.
\end{abstract}

Keywords: relative navigation; synchronization; flying object; communication network; anticollision system

\section{INTRODUCTION}

When designing the anti-collision system model, we assumed that if we know the position of at least two points in space and the distance of these points to an unknown point, we can calculate the position of the unknown point. In our case, we anticipate that, by transmitting communications messages by individual network users, our anti-collision system will know the location of those users. It will also be able to measure distances to these users because we have the time to send communications messages by individual users. RelNav positioning is based on measuring the distances to the broadcast sources by measuring the arrival time of the signals from these sources. In aviation, the position is most often expressed in geographical coordinates in WGS-84. We will use a rectangular coordinate system (ECEF) to design an anti-collision system [1].

\section{PROPOSAL OF MODEL FOR THE ANTI-COLLISION SYSTEM}

Suppose all users in the communications network in fig. no. 1 broadcasts, at short intervals, a position report. The propagation time of the signal from one user to the anti-collision system is directly proportional to the distance of the receiver of that system from the source of the broadcast (SoB). By measuring the distance of several users of the aviation communication network to the anticollision system, it is possible to determine its position.

If we know the coordinates of individual users of the aviation communication network (xi, yi, zi) and the distance of the anti-collision system from these users, we can determine its position $\mathrm{P}$ with coordinates $(\mathrm{x}, \mathrm{y}, \mathrm{z})$. We calculate $\mathrm{P}$ on the basis of a three-unknown system of four equations. Equations have the form [2]:

$d_{i}=\sqrt{\left(x-x_{i}\right)^{2}+\left(y-y_{i}\right)^{2}+\left(z-z_{i}\right)^{2}} \quad$, where $\mathrm{i}=1,2,3,4$

The location measurement problem would be relatively simple if the time base (clock) of all users were synchronous. The main problem is the time that elapses between sending the message and receiving it by the user receiver. The user sends a message at ti. The message will be received by the receiver at time tp. [2][9] 
If the propagation rate of electromagnetic waves c (light velocity in vacuum $=299,792,458 \mathrm{~m} / \mathrm{s}$, about $3 \times 108 \mathrm{~m} / \mathrm{s}$ ) is known, we can determine the distance between the broadcast source and the receiver of the user as follows:

$d_{i}=c\left(t_{p}-t_{i}\right)=c \tau_{i}$, , kde $\mathrm{i}=1,2,3,4$

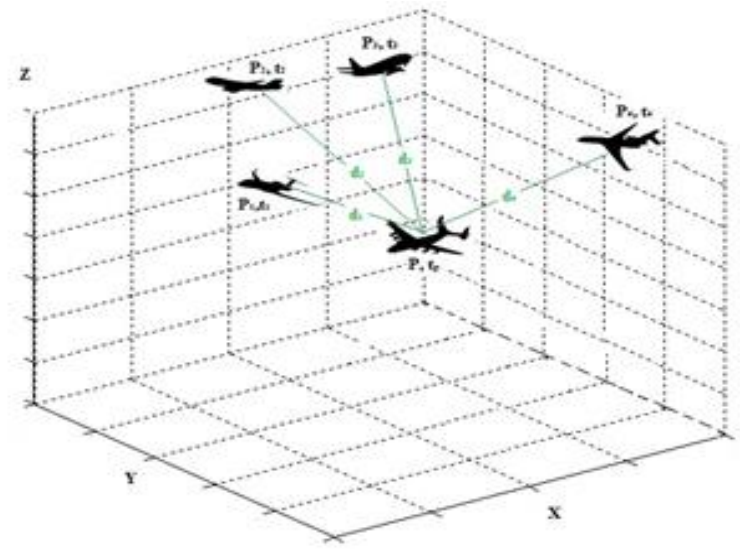

Figure 1 The principle of positioning in the relative navigation system [4]

Fig. 1 shows the air situation in the aviation communication network.

Symbols used:

$\mathrm{P}$ - aircraft position with anti-collision system

P1-4 - Users 1-4 location on the communication network

t1-4 - times when messages was sent

d1-4 - distances of users from the anti-collision system

The calculated distance is loaded with a number of errors that reduce measurement accuracy. That's why we call this distance pseudo-distance. Fig. no. 2 is a pseudo-position shown in black as di. The most significant error in distance measurement is the unsynchronicity of time base receivers of individual users. The time base of the receiver is shifted by an unknown time interval $\Delta \mathrm{t}$, which can be recalculated to the distance by the relation $\mathrm{b}=\mathrm{c} . \Delta \mathrm{t}$.

The actual distance will be: $\quad D_{i}=d_{i}-b$

where:

$d_{i}-$ measured pseudo-distance, $D_{i}-$ actual distance, $\Delta d_{i}$ - error of pseudo-distance measurement. .

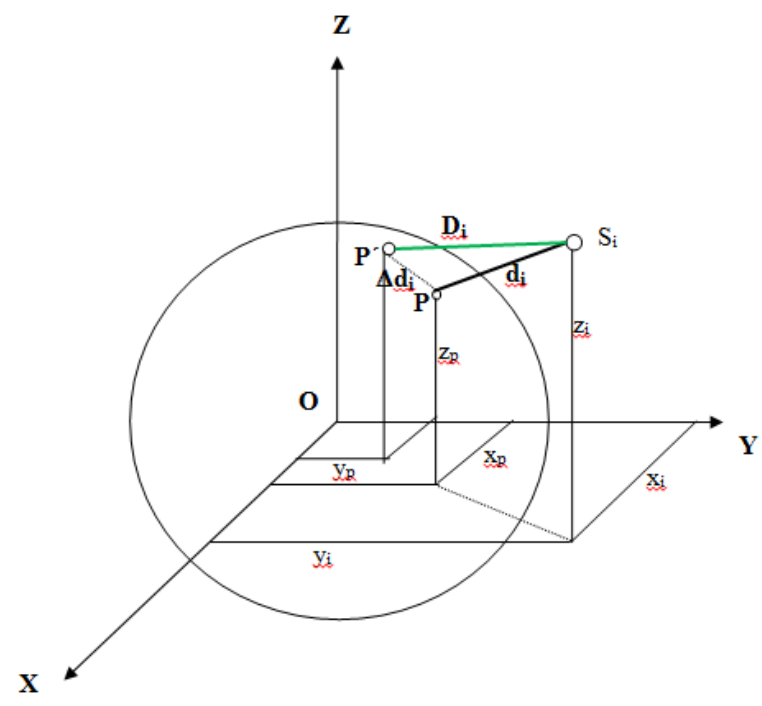

Figure 2 Actual distance and pseudo-distance [3] 
Unknown user coordinates include unknown $b$, and we need a total of four form equations to calculate the location:

$\left(d_{i}-b\right)=c .\left(\tau_{i}-\Delta t\right)=\sqrt{\left(x-x_{i}\right)^{2}+\left(y-y_{i}\right)^{2}+\left(z-z_{i}\right)^{2}}$, where $\mathrm{i}=1,2,3,4$

after adjustment we get:

$\left(x-x_{i}\right)^{2}+\left(y-y_{i}\right)^{2}+\left(z-z_{i}\right)^{2}-\left(b-d_{i}\right)^{2}=0$, where $\mathrm{i}=1,2,3,4$

$\mathrm{x}, \mathrm{y}, \mathrm{z}-$ position of the anti-collision receiver

$\mathrm{x}_{\mathrm{i}}, \mathrm{y}_{\mathrm{i}}, \mathrm{z}_{\mathrm{i}}-$ position of the $\mathrm{i}$-th user

$\mathrm{d}_{\mathrm{i}}-$ measured pseudo-distance from the anti-collision system to the user

$\tau_{\mathrm{i}}-$ signal propagation time from $\mathrm{i}$-th user to anti-collision system $\mathrm{P}(\mathrm{x}, \mathrm{y}, \mathrm{z})$

$\Delta \mathrm{t}$ - the time interval by which the receiver's time base is shifted

$\mathrm{b}-$ shift the time base of the receiver converted to distance

\section{GENERAL MODEL OF MOVING FLIGHT OBJECT IN SPACE}

The simulation model is based on the mathematical description (model), the current idea of the assumed system and its movement. We are considering the case that the modeled scene is threedimensional and finally we want to create a three-dimensional representation in a geocentric coordinate system (Earth-Centered, Earth-Fixed). It is a three-dimensional coordinate system with center in Earth's center of gravity. The $\mathrm{X}$-axis of the system passes through the intersection of the zero meridian and the equator, the $\mathrm{Y}$-axis points from west to east, the $\mathrm{Z}$-axis has a north-south direction. It is a rectangular coordinate system and is shown in fig. 3. [6] [7]

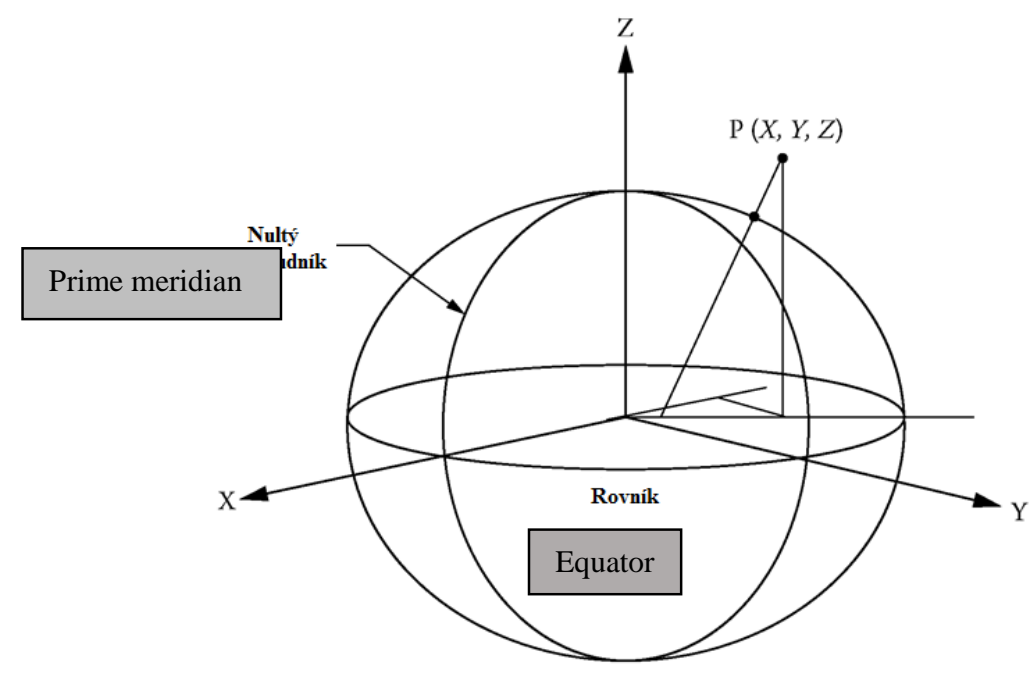

Figure 3 ECEF geocentric coordinate system [4]

The FO motion model is designed to verify the principle of the relative navigation system operating in the aviation communications network. The FO motion model is used to obtain information about the geocentric position of users (FO) in space. We've abstracted from FO forces in flight. For the purpose of simulating a relative navigation system, we may consider this fact to be irrelevant.

To clarify the principle of the FO motion model, we have chosen a real point on Earth to which we will place FO and simulate its next motion. As the starting point (starting point) of FO we chose the point of reference of Košice airport and altitude of $1700 \mathrm{~m}$. We consider these coordinates as reference. Table no. 1, the reference point data is entered.

We are starting to model the FO track and we use modeling or local coordinates for each part of its movement (ENU). For the motion model we chose a flight consisting of straightforward flight and two 
turns. As a result, it will be possible to evaluate the accuracy of positioning not only for the straightflight, but also for the manoeuvring parts of the flight.

Table 1 Initial coordinates (reference point)

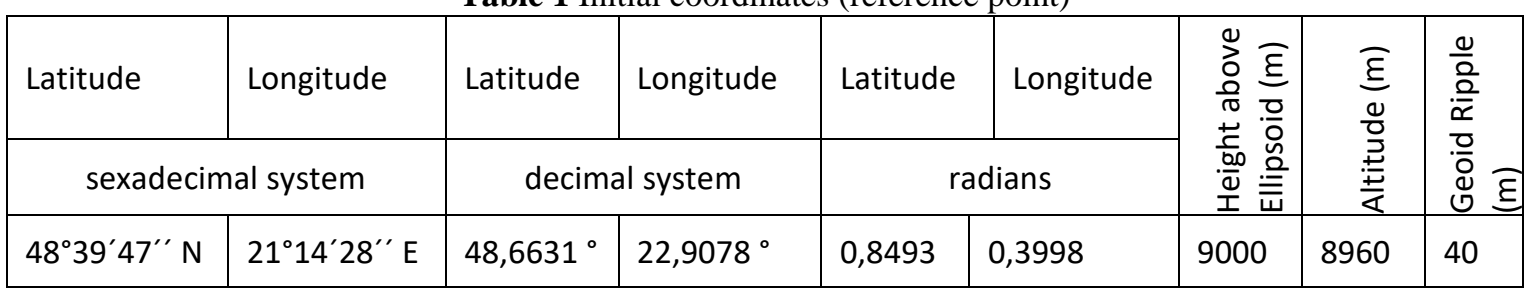

To begin with, it should be noted that the created model is flexible and can be modified and used to model the motion of any FO located on Earth, i. its initial coordinates are in the geodetic coordinate system back to WGS-84. Input parameters that can be changed according to current requirements are [5][9]:

- initial FO position,

- the duration of the movement or any part of it,

- motion trajectory,

- bend radius.

When modeling, we consider only local movement. This means that the resulting FO coordinates are not backward with the WGS-84.

The first phase of the LO movement. $9000 \mathrm{~m}$. The altitude does not change.

$X=370 \mathrm{~m}, \mathrm{y}=150 \mathrm{~m}, \mathrm{z}=9000 \mathrm{~m}$.

Before the first phase of LO movement (straightforward motion):

$\mathbf{t}=\mathbf{1}: \mathbf{3 7 5}$

$\mathrm{x}(\mathrm{t})=370+\mathrm{t}$

$\mathrm{y}(\mathrm{t})=150+\mathrm{t}$

$z(t)=9000$

end;

Second phase of motion FO - turn left is $100 \mathrm{~s}$ in altitude $9000 \mathrm{~m}$.

For the second phase of FO movement:

$\mathbf{k}=\mathbf{1}: \mathbf{1 0 0}$;

$\mathrm{x}(\mathrm{k}+\mathrm{t}+\mathrm{i})=\mathrm{x}((\mathrm{k}+\mathrm{t}+\mathrm{i})-1)-(3 * \mathrm{r}) * \cos (\mathrm{ink}(\mathrm{k})+\mathrm{beta}) ;$

$\mathrm{y}(\mathrm{k}+\mathrm{t}+\mathrm{i})=\mathrm{y}((\mathrm{k}+\mathrm{t}+\mathrm{i})-1)+(3 * \mathrm{r}) * \sin (\mathrm{ink}(\mathrm{k})+$ beta $)$;

$\mathrm{z}(\mathrm{k}+\mathrm{t}+\mathrm{i})=9000$

The third phase of FO-turn is $100 \mathrm{~s}$ at an altitude of $9000 \mathrm{~m}$.

For the third phase of FO movement

$\mathbf{k}=1: \mathbf{1 0 0}$;

$\mathrm{x}(\mathrm{k}+\mathrm{t}+\mathrm{i})=\mathrm{x}((\mathrm{k}+\mathrm{t}+\mathrm{i})-1)-\left(3^{*} \mathrm{r}\right) * \cos (\mathrm{ink}(\mathrm{k})+$ beta $) ;$

$\mathrm{y}(\mathrm{k}+\mathrm{t}+\mathrm{i})=\mathrm{y}((\mathrm{k}+\mathrm{t}+\mathrm{i})-1)+(3 * \mathrm{r}) * \sin (\operatorname{ink}(\mathrm{k})+\mathrm{beta}) ;$

$\mathrm{z}(\mathrm{k}+\mathrm{t}+\mathrm{i})=9000$

end;

where:

$\mathrm{x}, \mathrm{y}, \mathrm{z}$ - coordinates for FO movement

$\mathrm{t}, \mathrm{i}, \mathrm{k}$ - repeat counter

ink - step vector for generating movements of the same length

beta - angle increment

$\mathrm{r}$ - radius 
The local FO motion model must be transferred to the geodetic coordinate system. The geodetic coordinate system (LLH) is shown in FIG. 4 and is used on most maps and is also used in data processing in autonomous navigation and radio aeronautical navigation equipment. The geodetic coordinate system determines the point position on the ellipsoid surface. The coordinates are latitude $\phi$, longitude $\lambda$ and ellipsoidal height $h$. The difference of the ellipsoidal height $h$ and the normal height $\mathrm{H}$ is the so-called. the height anomaly $\varsigma$ for which: [8]

$\varsigma=h-H$,
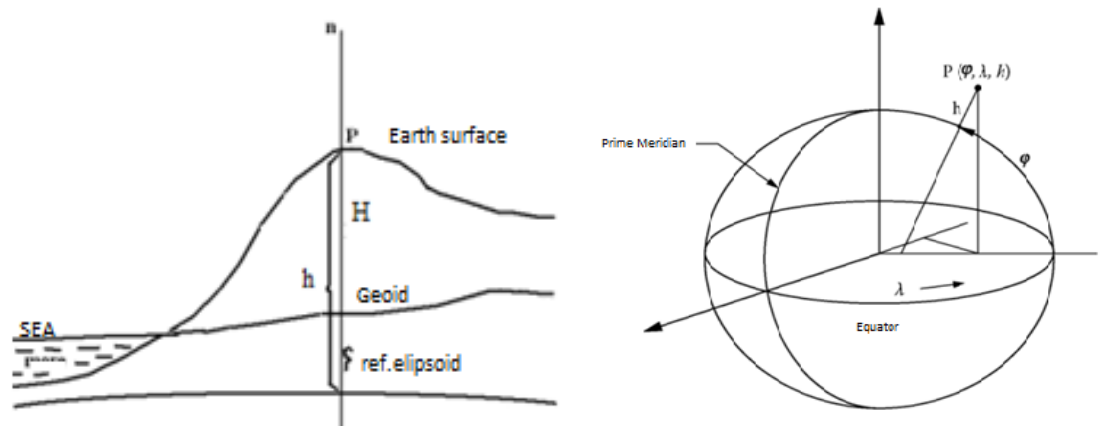

Figure 4 Geodetic coordinate system [8]

where:

$\mathrm{H}$ - altitude (normal height),

$\varsigma$ - height of geoid, resp. Quasigeoid.

Before transforming the coordinates, it is necessary to realize the types of heights we will work with. Transformation functions work with ellipsoidal heights. In practice, however, altitude systems built on the basis of altitudes $\mathrm{H}$, which are related to the geoid, are used. Geoid is difficult to define mathematically, and so is called. Quasigeoid. It is a mathematically definable area and is referred to as so-called. normal heights. Terrain density and topography models, Earth satellite models, gravity acceleration ground measurements are used to define the surface quasi-period. Referring to the aeronautical Information Manual Part 3. AD 2.2 is a geoid ripple at Kosice Airport $40 \mathrm{~m}$. This fact must be taken into account when transforming coordinates and simulation [5][6][11].

As we mentioned at the beginning of the chapter, our task is to display the FO motion model in the geocentric coordinate system. However, the initial coordinates, respectively. the starting point coordinates are specified in the geographic coordinates and the generated model represents only local motion not related to WGS-84. Therefore, we must apply the functions for the given coordinate transformations. The process of transforming the coordinates of the resulting motion FO with the origin in the specified starting coordinates into the geocentric coordinate system and is divided into the following steps [4]:

1. Transform geodetic starting point coordinates into geocentric coordinate system (ECEF).

2. Transformation of local motion model coordinates into geocentric coordinate system (ECEF).

3. Establishing a local FO local motion model to a starting point.

4. Transformation of the resulting FO model into geodetic coordinates (for real representation of FO motion on Earth).

5. Transformation back to the geocentric coordinate system (ECEF) for the purpose of our task

For individual coordinate transformations we used the following matlab functions:

- Function for transforming initial coordinates from LLH to ECEF: 11h2xyz

The function is used to convert geographic coordinates (latitude, longitude, and height in WGS-84) to rectangular geocentric coordinates $\mathrm{X}, \mathrm{Y}, \mathrm{Z}$ in meters. The earth. width, length is given in radians and the ellipsoidal height is given in meters.

- Function for transforming local motion coordinates from ENU to ECEF: enu2xyz 
ENU is a local topocentric coordinate system with the origin of the coordinate system at the reference point. The $\mathrm{U}$ axis passes through the topocentre, and the $\mathrm{E}$ and $\mathrm{N}$ axes are and perpendicular to the $\mathrm{U}$ axis, with the $\mathrm{E}$ axis facing east and the $\mathrm{N}$ axis pointing north. Both coordinate systems are shown in FIG. 5. Both input and output coordinates are expressed in meters relative to the origin of the coordinate system. [7]

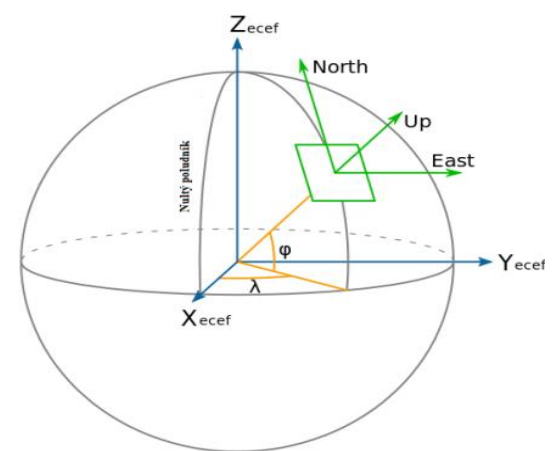

Figure 5 Coordinate systems ECEF a ENU [7]

- Function to transform coordinates of the resulting LO motion model from ECEF to LLH: xyz21lh Using this function, we are able to determine the real position of our FO on the map, because the coordinates are ground. width, ground. length in radians and ellipsoidal height FO in meters related to the WGS-84 reference system. The solution to this problem is to determine and display the LO position in the center coordinate system in the center of gravity of the Earth (ECEF). Therefore, it is necessary to transform the coordinates of the resulting FO model into the Earth's system again using the llh2xyz (lat, long, h) function. [5] [8]

After individual transformations we can visualize the motion model, where we will work with the geocentric coordinate system ECEF. The FO position will be determined in each second by the coordinates $\mathrm{x}, \mathrm{y}, \mathrm{z}$ (in meters) with the center of the coordinate system in the Earth's center of gravity. The three-part LO simulation itself is shown in Figure 4. The initial coordinates are listed in Table 1.
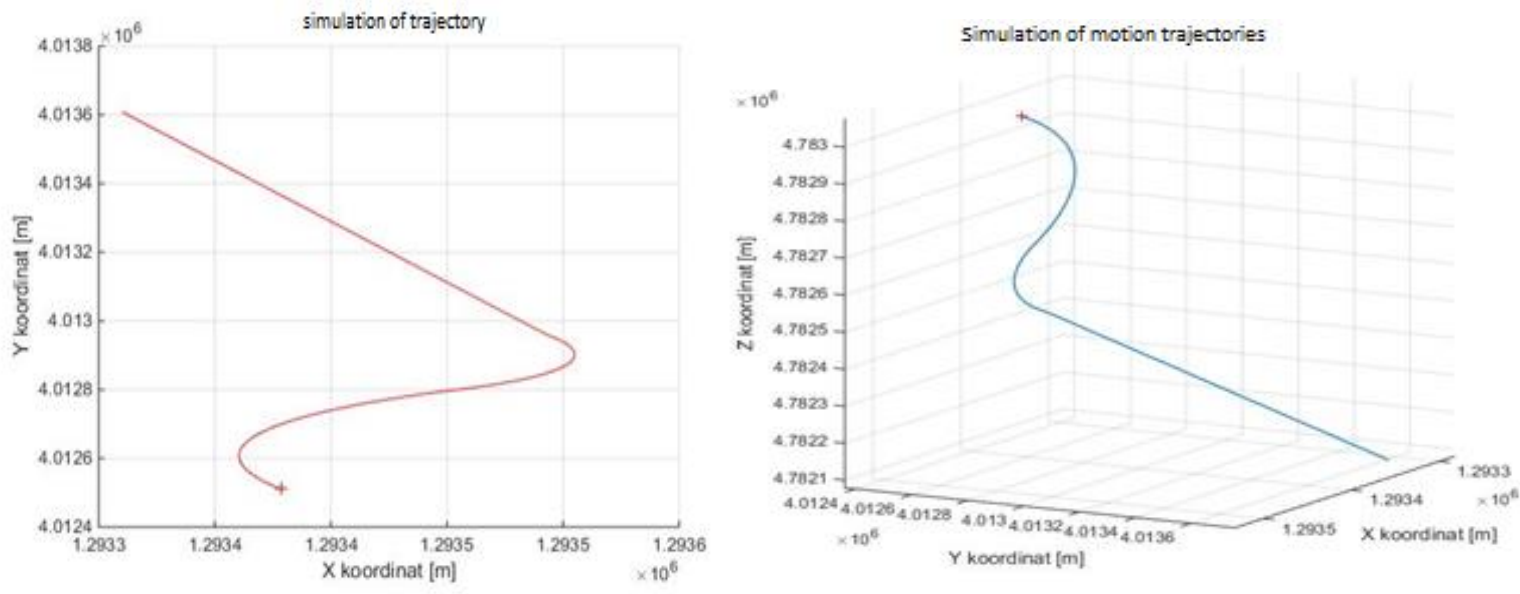

Figure 6 The trajectory of movements FO [3]

\section{CONCLUSION}

Using the algorithms mentioned in the second and third chapter of this thesis, it is possible to design the architecture of the anti-collision system. Based on the principle of relative navigation, the anti-collision system is able to determine its position vis-à-vis other users in the aviation communications network. From the broadcast messages, the individual users of the aviation communication network can determine their location. This anti-collision system will get an overview of the air situation around the aircraft on which it is installed. By displaying the acquired data through 
a suitable display device, the pilot will have information about the real air situation. The system architecture can be supplemented by signaling collision situations in the airspace, the possibility of predicting the trajectory of the aircraft flight due to the air situation. The results of the modeling of the motion of the flying object, which are shown in Figure 6, confirm that the created model allows to simulate the flight trajectory of the flying object. It is clear from the picture that the flight trajectory consists of a straightforward flight and two turns. The simulation confirmed that the created model would be suitable for the design of the anti-collision architecture.

\section{References}

[1] M. Dzunda, Radioengineering Accurancy and resistance of the radionavigation distance meter against chaotic impulse interference when using binary carrier signals. 1996

[2] M. Dzunda, .; D.Cekanova, .; L.Cobirka, .; et al. Protection Against High-Frequency Radiation of Aviation Electronic Support Systems Used in Air Transport Transnav-International Journal On Marine Navigation And Safety Of Sea Transportation Volume: 12 Issue: 1 Pages: 183186 Published: 2018

[3] M. Dzunda,.; V. Humenansky, .Accuracy of Relative Navigation in Automated Systems of Data Communication Transnav-International Journal on Marine Navigation and Safety of Sea Transportation Volume: 2 Issue: 2 Pages: 161-163 Published: JUN 2008

[4] T. Haberkorn, I. Koglbauer, R. Braunstingl, B. Prehofer, Requirements for future collision avoidance systems in visual flight: a human-centered approach, IEEE Trans. Hum.-Mach. Syst. 43 (6) (2013) 583-594.

[5] M. Webster, M. Fisher, N. Cameron, M. Jump, Formal methods for the certification of autonomous unmanned aircraft systems, Comput. Saf. Reliab. Secur. 6894 (2011) 228-242.

[6] M. Dzunda, A. Hrban, 1998 Accuracy of the passive tracking systems 12th International Conference on Microwaves and Radar, MIKON 1998

[7] M. Dzunda, N. Kotianova, Selected Aspects of Applying Communication Technology to Air Transportation Conference: International Conference on Computer Science and Information Engineering (CSIE) Location: Bangkok, THAILAND Date: JUN 28-29, 2015

International Conference on Computer Science and Information Engineering (CSIE 2015) Pages: 17 Published: 2015

[8] M. Dzunda, .; Z. Csefalvay, .; N. Kotianova, .Target Localization by Method of Intersections of the Ellipses Using Two UWB Radar Systems International Conference on Advanced Educational Technology and Information Engineering (AETIE)Location: Beijing, PEOPLES $\mathrm{R}$ CHINA Date: MAY 17-18, 2015 Pages: 697-706 Published: 2015

[9] F. Adamčík, J. Galanda, R. Sulej, M. Jezný. Applied Algorithmization in Optimization of Airport Processes Simulation Models, Magazine of Aviation Development. Vol. 5, no. 4 (2017), pp. 29-33.

[10] M. Dzunda, ; N. Kotianova, The accuracy of relative navigation system Conference: International Conference on Engineering Science and Production Management (ESPM) Location: SLOVAKIA Date: APR 16-17, 2015 Pages: 369-375 Published: 2016

[11] E. Jenčová, J. Galanda, R. Šulej, J. Vagner. Optimalization of the number of aircraft motions by Means of the sho simulation model, Acta Avionica. Roč. 19, č.2 (2017), pp. 58-63

[12] E. Jenčova,..J. Vagner,.,P. Korba, ,P. Košcák,, M. Hovanec. Comparison of the accuracy of selected forecasting methods, Transport Means - Proceedings of the International Conference 2018October, pp. 1494-1499

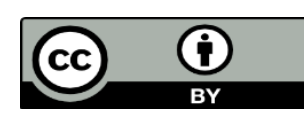

The article is licensed under a Creative Commons Attribution 4.0 International License 